\title{
Curricularização da extensão: uma proposta para o curso de administração
}

\section{Extension curricularization: a proposal for the administration course}

DOI: 10.54019/sesv3n1-002

\section{Gabriella Depiné Poffo}

Doutora em Administração

Centro Universitário Avantis - UNIAVAN

E-mail: gabrielladepine@gmail.com

\section{Gisele Kruger}

ORCID 0000-0002-1187-2977

Mestranda em Administração - ênfase em Gestão de Organizações de Educação

Superior

Especialista em Direito Educacional, Especialista em Gestão em Pedagogia Empresarial e Educacional, Especialista em Gestão de Instituições de Ensino

Faculdade Pedro Leopoldo - FPL

E-mail: contato.giselek@gmail.com

\section{Bruna Jaime Feiden}

Especialista em Supervisão Escolar

Centro Universitário Avantis - UNIAVAN

E-mail: bfeiden.efi@gmail.com

\section{Marcelo menezes da luz machado}

Mestre em políticas públicas

Centro universitário avantis - uniavan

E-mail:Mmavantis@gmail.com

\section{Isabel regina depine poffo}

Mestre em engenharia ambiental

Centro universitário avantis - uniavan

E-mail: Depinepoffo@gmail.com

\section{Fernanda chiaratti}

Doutora em psicologia da educação

Centro universitário avantis - uniavan

E-mail: Fernanda.chiaratti@uniavan.edu.br

\section{RESUMO}

Com o intuito de aperfeiçoar a gestão universitária, o objetivo principal desta pesquisa é apresentar uma proposição da implantação da curricularização da extensão na matriz curricular para o curso de Administração conforme a Resolução CNE/CES no 7 de 18 dezembro de 2018. Com a promulgação 
legislativa, o Ministério da Educação, têm exigido além das obrigações de ensino, a ampliação da oferta da extensão e pesquisa em condicionamento com a comunidade externa. A finalidade principal prevista nesta resolução se baseia na disciplina de atividades práticas curriculares voltadas para as atividades extensionistas além do conteúdo teórico obrigatório de cada curso de graduação. Como forma de condicionar este estudo, será necessária uma compreensão da evolução legislativa baseada em aspectos históricos, a descrição da Resolução CNE/CES no 7 e a estruturação de uma proposição para matriz curricular do curso de administração. Em reuniões de grupo focal foi planejado a execução de um projeto piloto para oferta em 2021/1 conforme pode ser identificado no estudo a seguir. Como conclusão do estudo é possível identificar que a implantação dessa legislação fortalecerá a formação do acadêmico desenvolvendo novas habilidades técnicas e profissionais, qualificando o aluno para o mercado de trabalho mais competitivo, dinâmico e inovador.

Palavras-chave: Legislação de Ensino Superior, Curricularização da Extensão, Gestão universitária.

\section{ABSTRACT}

In order to improve university management, the main objective of this research is to present a proposal for the implementation of the extension curricularization in the curriculum for the Administration course in accordance with Resolution No. 7 of December 18, 2018 of the National Council of Education. With the enactment of legislation, the Ministry of Education has demanded, in addition to teaching obligations, the expansion of the extension and research offer in connection with the external community. The main purpose provided for in this resolution is based on the discipline of practical curricular activities aimed at extension activities in addition to the mandatory theoretical content of each undergraduate course. As a way of conditioning this study, an understanding of the legislative evolution based on historical aspects, the description of Resolution No. 7/2018 and the structuring of a proposal for the curriculum of the administration course will be necessary. In focus group meetings, it was planned to carry out a pilot project for the offer in $2021 / 1$ as can be identified in the study below. As a conclusion of the study, it is possible to identify that the implementation of this legislation will strengthen academic training by developing new technical and professional skills, qualifying students for the most competitive, dynamic and innovative job market.

keywords: Higher Education Legislation, Extension Curriculum, University management.

\section{INTRODUÇÃO}

A partir dos avanços e atualizações advindas do Ministério da Educação, recentemente, houveram consideráveis avanços regulatórios, os quais buscam atingir um processo de ensino e aprendizagem eficiente para o mercado de trabalho. Segundo a Resolução CNE/CES n 7, publicada no Diário Oficial da União (DOU) em 18 de dezembro de 2018, as Instituições de Ensino Superior 
devem implementar, na carga horária dos cursos de graduação, o mínimo de 10\% destinados exclusivamente para atividades de extensão.

Esta definição, de ao menos $10 \%$ da carga horária contida nas matrizes curriculares dos cursos de graduação, faz parte da Meta 12.7 do Plano Nacional de Educação (PNE) 2014-2024 instituido pela Lei no 13.005/2014. Contudo, apesar do PNE prever até 2024 para a sua implementação integral, as instituições já devem apresentar em seus currículos o percentual mínimo até final de 2022 conforme prorrogação realizada pela Resolução CNE/CES nำ1/2020.

Concretizando a importância da exploração dos estudos nessa área tão emergente, o presente artigo visa apresentar como temática principal uma proposta para implantação da curricularização da extensão na matriz do curso de Bacharelado em Administração, na modalidade presencial, do Centro Universitário Avantis (UNIAVAN), localizado na cidade de Balneário Camboriú, no estado de Santa Catarina.

Este artigo é apresentado metodologicamente como um estudo de caso aplicado no curso de Administração, modalidade presencial. É um estudo de natureza básica e, por utilizar bases de referências documentais advindas de grupos focais, os quais participavam diretores e gestores da IES para discussão e avaliação da implantação da legislação instituída pelo MEC, baseia-se em um estudo qualitativo. Ainda, através dos caminhos metodológicos, utilizou como base para os objetivos a pesquisa descritiva e expositiva e, como procedimentos técnicos bibliográfica, documental e grupo focal.

A concorrência acirrada entre as IES privadas, particulares em sentido estrito, associadas às exigências do Ministério da Educação tem feito com que as referidas instituições, para ter continuidade, dediquem-se, obstinadamente, à busca e à efetivação de vantagens competitivas sustentáveis, passando a preocupar-se com a satisfação de seus alunos (FARIA et al., 2006). Não obstante a isso, as instituições precisam cumprir as exigências impostas pelo ministério sem ocasionar prejuízos aos acadêmicos, professores e comunidade em geral, principalmente focando em manter a qualidade da formação dos seus alunos para o mercado de trabalho.

Para nortear essa pesquisa, utiliza-se como objetivo principal a proposição de uma matriz curricular para o curso de Administração com a implantação da 
legislação do MEC, Resolução CNE/CES no 7 de 18 dezembro de 2018. E, a fim de atingir o objetivo proposto, o presente estudo analisa a evolução da legislação do ensino superior para compreender sua definição, seus modelos e importância para as organizações de ensino. No segundo momento, estuda-se algumas concepções da Resolução CNE/CES no 7/2018, em relação a sua promulgação e previsão de aplicação da legislação pelas IES no Brasil. Em seguida, apresentase a implantação desses aspectos legislativos em vigor com a implantação da curricularização na matriz curricular do curso de administração no ensino superior, apresentando uma proposta de matriz curricular que atenda a legislação em vigor identificando suas funcionalidades, como se propõe neste estudo.

\section{FUNDAMENTAÇÃO TEÓRICA}

Os tempos atuais trouxeram uma nova forma de estudar e aprender no ensino superior, muito diferente das encontradas entre as décadas de 1980 e 1990. Nesta época, os processos seletivos eram concorridos e estudar em uma IES era algo inesperado nas famílias. Com a promulgação da Lei de Diretrizes e Bases da Educação (LDB) Lei n 9.394/1996 a oferta do ensino superior sofreu um aceleramento, houve uma expansão na oferta de ensino. Ou seja, os serviços educacionais de ensino superior entraram em uma nova era. Os autores Walter, Tontini e Domingues (2005), afirmam que o sistema educacional se aproxima, cada vez mais, de um mercado onde a qualidade dos serviços e a satisfação dos clientes são fundamentais para a sobrevivência das IES.

De acordo com censo, 35\% dos alunos são a primeira geração de ensino superior da família. O cenário é novo, dinâmico e competitivo, em 2014 mais de 3,1 milhões de alunos ingressaram nos cursos superiores no Brasil (INEP, 2016). Inclusive, o número de matrículas em cursos presenciais das IES públicas e privadas cresceu $129 \%$ nos últimos treze anos, para as matrículas de cursos à distância no período de 2009 a 2013, o crescimento registrou 37,5\%.

$\mathrm{E}$, de acordo com o número de IES no Brasil esteve em constante ascensão na última década com um crescimento de 102,6\%, hoje temos cerca de 2.368 IES devidamente credenciadas e em funcionamento no Brasil, sendo que destas $87,4 \%$ das IES são privadas (INEP, 2016). O número de matrículas supera 7,8 milhões de alunos no ensino superior. As matrículas de graduação da rede privada, alcançaram em 2014, a maior participação percentual dos últimos anos, 
74,9\%. 83,9\% das IES brasileiras são faculdades, mas, nessa organização acadêmica, estão matriculados $28,6 \%$ dos estudantes.

Com isto, é inerente a importância de constantemente atualizar as políticas educacionais, a fim de contemplar as atualizações da sociedade. Contudo, a mudança não pode atingir negativamente os alunos, fazendo com que as instituições procurem métodos qualificados de colocar em prática o que está presente nas legislações.

\subsection{Evolução Da Legislação No Ensino Superior}

A expansão no ensino superior brasileiro está marcada pelo seu crescimento nos últimos anos, proporcionado pela LDB (Lei no 9394/1996. Embora a educação superior no Brasil ainda seja caracterizada como elitista (a taxa de pessoas cursando a educação superior é de 17,6\%) convivemos com novos formatos de IES, novos cursos, novos discentes, novas exigências da sociedade, do mercado e da globalização do ensino superior (MOROSINI, 2014).

Com a necessidade de tornar esse mecanismo de avaliação coeso e preciso, há uma reformulação constante do sistema de avaliação que pode ser observado no Quadro1:

Quadro 1: Evolução Histórica da Legislação ES no Brasil

\begin{tabular}{|c|l|}
\hline Programa Desenvolvido & \multicolumn{1}{|c|}{ Pontos Relevantes } \\
\hline $\begin{array}{c}\text { PARU - Programa de Avaliação da } \\
\text { Reforma Universitária (1983) }\end{array}$ & $\begin{array}{l}\text { Seu objetivo era a inserção do segmento em uma } \\
\text { dinâmica utilitarista e gerencial, fomentando práticas, } \\
\text { com participação ativa da comunidade acadêmica, } \\
\text { vinculadas á produção, à sistematização e à } \\
\text { disseminação do conhecimento no contexto das } \\
\text { instituiçães. O PARU durou apenas um ano, pois } \\
\text { houve falta do Ministério da Educação em consolidar } \\
\text { esse sistema. }\end{array}$ \\
\hline $\begin{array}{c}\text { CNRES - Comissão Nacional para a } \\
\text { Reformulação da Educação Superior } \\
\text { (1885) }\end{array}$ & $\begin{array}{l}\text { Instituída pelo Decreto no 91.177 de 29/03/1985, sua } \\
\text { finalidade é a democratização do país. A comissão } \\
\text { que perfilou o PARU serviu para construir um olhar } \\
\text { sistemático sobre avaliação institucional na } \\
\text { educação superior. }\end{array}$ \\
\hline $\begin{array}{c}\text { GERES - Grupo Executivo para a a } \\
\text { Reformulação da Educação Superior } \\
\text { (1986) }\end{array}$ & $\begin{array}{l}\text { Em 1986 o relatório apresenta o desenvolvimento de } \\
\text { indicadores de desempenho que auxiliassem o } \\
\text { fomento de identidade institucional, orientando o } \\
\text { financiamento e o repasse de recursos. Estruturou } \\
\text { uma discussão acerca da necessidade sobre o } \\
\text { controle de qualidade no âmbito institucional. }\end{array}$ \\
\hline $\begin{array}{l}\text { Pom a promulgação da constituição 1988, o PAIUB } \\
\text { Institucional das Universidades } \\
\text { Brasileiras (1988) }\end{array}$ & $\begin{array}{l}\text { ensejou ações proativas das instituiçães com a a } \\
\text { intenção de elevar o padrão de qualidade da } \\
\text { educação superior de modo a torná-la similar aos } \\
\text { países desenvolvidos. Seu foco era direcionado em } \\
\text { promover a legitimidade da avaliação, a continuidade }\end{array}$ \\
\hline
\end{tabular}




\begin{tabular}{|c|c|}
\hline & $\begin{array}{l}\text { da identidade institucional e não a premiação ou } \\
\text { punição da IES. }\end{array}$ \\
\hline $\begin{array}{c}\text { ENC - Exame Nacional de Cursos } \\
\text { (1995) }\end{array}$ & $\begin{array}{l}\text { Lei no } 9.131 \text { de } 24 / 11 / 1995, \text { podendo ser } \\
\text { considerado um marco histórico no desenvolvimento } \\
\text { da avaliação da educação superior contando com o } \\
\text { apoio do CNE. Principal mecanismo de avaliação } \\
\text { entre 1995-2003, conhecido como Provão, buscava } \\
\text { a interação entre o Ministério da Educação com as } \\
\text { IES. Sua operacionalização era uma prova aplicada } \\
\text { aos concluintes dos cursos de graduação. }\end{array}$ \\
\hline $\begin{array}{r}\text { LDB - Lei de Diretrizes } \\
\text { Educação (199 }\end{array}$ & $\begin{array}{l}\text { Aplicada como a principal legislação da educação, a } \\
\text { LDB Lei no } 9394 / 1996 \text { é pautada em amplo contexto } \\
\text { o processo de regulamentação. Seus procedimentos } \\
\text { permitiram a expansão do ensino superior, criação de } \\
\text { novos cursos e o aumento de vagas, e } \\
\text { consideravelmente o acesso ao ensino superior, } \\
\text { alterando todo o cenário brasileiro. Incorporou, ao } \\
\text { longo de sua tramitação, vários dispositivos à } \\
\text { educação superior, objetos de projetos de lei e de } \\
\text { decretos que a antecederam, contribuindo para a } \\
\text { consolidação de políticas e gestão da educação } \\
\text { superior. }\end{array}$ \\
\hline $\begin{array}{c}\text { SINAES - Sistema Nacional de } \\
\text { Avaliação da Educação Superior } \\
(2004)\end{array}$ & $\begin{array}{l}\text { O Sinaes em sua estrutura constitui-se da } \\
\text { experiência de diversos momentos históricos da } \\
\text { avaliação do Brasil. Promulgado através da Lei }{ }^{\circ} \\
10.861 \text { de 14/04/2004 apresenta como missão } \\
\text { avaliar a graduação valorizando aspectos indutores } \\
\text { da melhoria da qualidade da educação superior e da } \\
\text { formação acadêmica dos estudos brasileiros. }\end{array}$ \\
\hline $\begin{array}{l}\text { Decreto } n^{\circ} 5.773 \text { (2006) revogado } \\
\text { pelo Decreto 으 } 9.235 \text { (2017) }\end{array}$ & $\begin{array}{l}\text { A regulação se efetiva por meio de atos autorizativos } \\
\text { do funcionamento de IES e de cursos de graduação. } \\
\text { A supervisão se realiza com o objetivo de zelar pela } \\
\text { conformidade da oferta da educação superior no } \\
\text { sistema federal de ensino com a legislação aplicável. }\end{array}$ \\
\hline $\begin{array}{r}\text { Portaria Normativa } \\
\text { Revogado pelas Port } \\
n^{\circ} 11,21,22 \epsilon\end{array}$ & $\begin{array}{l}\text { Institui o e-MEC, sistema eletrônico de fluxo de } \\
\text { trabalho e gerenciamento de informações relativas } \\
\text { aos processos de regulação da educação superior no } \\
\text { sistema federal de educação. }\end{array}$ \\
\hline $\begin{array}{c}\text { Portaria Normativa } \mathrm{n}^{0} 1 \\
\text { Revogado pela Portaria } \mathrm{Nc} \\
23 / 2017\end{array}$ & $\begin{array}{l}\text { Altera o inciso IV do art. } 57 \text { da Portaria Normativa } \\
\text { MEC no } 40 .\end{array}$ \\
\hline Portaria $n^{0} 1.38$ & $\begin{array}{l}\text { Aprova, em extrato, os indicadores do Instrumento } \\
\text { de Avaliação de Cursos de Graduação para os atos } \\
\text { de autorização, reconhecimento e renovação de } \\
\text { reconhecimento nas modalidades presencial e a } \\
\text { distância do Sistema Nacional de Avaliação da } \\
\text { Educação Superior - Sinaes }\end{array}$ \\
\hline $\begin{array}{l}\text { Portaria Normativa no } 20 \text { (2017) } \\
\text { republicada } \\
\text { Alterada pela Portaria Normativa oㅡ } \\
\quad 741 / 2018\end{array}$ & $\begin{array}{l}\text { A Portaria Normativa } \mathrm{n}^{\circ} \quad 20 \text { dispõe sobre os } \\
\text { procedimentos e o padrão decisório dos processos } \\
\text { de credenciamento, recredenciamento, autorização, } \\
\text { reconhecimento e renovação de reconhecimento de } \\
\text { cursos superiores, bem como seus aditamentos, nas } \\
\text { modalidades presencial e a distância, das } \\
\text { instituições de educação superior }\end{array}$ \\
\hline Portaria Normativa no 21 (2017) & $\begin{array}{l}\text { A Portaria Normativa no } 21 \text { trata sobre o sistema e- } \\
\text { MEC e sobre o Cadastro Nacional de Cursos e } \\
\text { Instituições de Educação Superior, o Cadastro e- } \\
\text { MEC }\end{array}$ \\
\hline Portaria Normativa № 22 (2017) & $\begin{array}{l}\text { Já a Portaria Normativa no } 22 \text { dispõe sobre os } \\
\text { procedimentos de supervisão e monitoramento de }\end{array}$ \\
\hline
\end{tabular}




\begin{tabular}{|c|l|}
\hline & $\begin{array}{l}\text { instituições de educação superior e de cursos } \\
\text { superiores de graduação e de pós-graduação lato } \\
\text { sensu, nas modalidades presencial e a distância }\end{array}$ \\
\hline $\begin{array}{l}\text { Pa Portaria Normativa no } 23 \text { o MEC dispõe sobre o } \\
\text { Alterada pela Portaria Normativa } n^{\circ} \text { - }\end{array}$ & $\begin{array}{l}\text { fluxo dos processos de credenciamento e } \\
\text { recredenciamento de instituições de educação } \\
\text { superior e de autorização, reconhecimento e } \\
\text { renovação de reconhecimento de cursos superiores, } \\
\text { bem como seus aditamentos }\end{array}$ \\
\hline
\end{tabular}

Fonte: Poffo, 2018.

Diante do quadro apresentado, evidencia-se que o papel do Ministério da Educação é lastreado pelo aperfeiçoamento do ensino superior brasileiro. Em seus aportes históricos sua preocupação se concentra vigorosamente em qualidade do ensino, preocupação com a expansão do ensino superior e a sua legitimidade. Além do mais, a preocupação do MEC se concentra no aperfeiçoamento continuo com o mercado de trabalho, legitimando a importância da formação do individuo para sua ascensão profissional.

Os autores Garcia Vianna, e Suñé (2012) afirmam que o Sistema Nacional de Avaliação no Ensino Superior (SINAES) tem caráter formativo que utiliza os resultados da avaliação para projetar planos, programas, projetos e ações de melhorias contínuas da educação no País. Instituído através da Medida Provisória nº 147, de 15 de dezembro de 2003, e aprovado pela Lei ํㅜ 10.861, de 14 de abril de 2004, o SINAES apresenta diretrizes definidas pela Comissão Nacional de Avaliação da Educação Superior (CONAES), cabendo ao Instituto Nacional de Estudos e Pesquisas Educacionais Anísio Teixeira (INEP), por meio de sua Diretoria de Avaliação da Educação Superior (DAES), a organização do procedimento avaliativo.

Dias Sobrinho (2010), relata que o SINAES trouxe uma inovação significativa para o cenário educacional brasileiro, permitindo que as IES usufruíssem da possibilidade de desenvolver, aplicar, acompanhar e avaliar um projeto institucional. Dentre os mecanismos de avaliação instituídos pelos SINAES, a Avaliação Institucional, tem se mostrado indispensável, mas também difícil. Lins, Teixeira e Barbosa (2005) explicam que apesar dos esforços contra e, principalmente, a descontinuidade, bem como a luta e o idealismo de poucos tem feito com que ao menos sejam discutidos todos estes fatores para que possa ocorrer um crescimento e também novos direcionamentos, uma vez que estas novas aberturas estimulam idealizações e tentativas de avaliações diferenciadas 
em diferentes instituições do país.

Dada a relevância dos itens estruturados pelo SINAES no processo de avaliação, os itens serão apresentados no quadro a seguir:

Quadro 02: Itens da Avaliação SINAES

\begin{tabular}{|c|c|}
\hline Autoavaliação & $\begin{array}{l}\text { Autoavaliação institucional é conduzida pela Comissão Própria de Avaliação } \\
\text { - CPA. É realizada in loco por especialistas externos à instituição, mediante } \\
\text { análise de documentos, interlocução com diferentes membros de diferentes } \\
\text { segmentos da IES, bem como da comunidade regional ou local. Avaliação } \\
\text { interna objetiva: } \\
\text { 1-Identificar a finalidade e relevância científica e social das atividades } \\
\text { realizadas no conjunto das instituições, bem como o seu cumprimento ou não; } \\
\text { 2-Identificar as causas dos problemas; } \\
\text { 3-Aumentar a capacidade profissional do corpo docente, dos técnico- } \\
\text { administrativos e administradores; } \\
\text { 4-Fortalecer a cooperação entre os diversos membros institucionais, de modo } \\
\text { a tornar mais efetiva a ligação da instituição com a comunidade; } \\
5-P r e s t a r \text { contas à sociedade. } \\
\text { O processo de avaliação é contínuo e deve ser postado até o dia } 31 \text { de março } \\
\text { de cada ano no sistema e-MEC. } \\
\text { Sua finalidade é desenvolver o processo permanente de aperfeiçoamento das } \\
\text { funções de ensino, pesquisa, extensão, como, também, perceber as } \\
\text { potencialidades e limitações da instituição. A CPA é responsável pela } \\
\text { condução dos processos avaliativos, pela sistematização, bem como } \\
\text { responsável pelas informações repassadas ao INEP. }\end{array}$ \\
\hline & 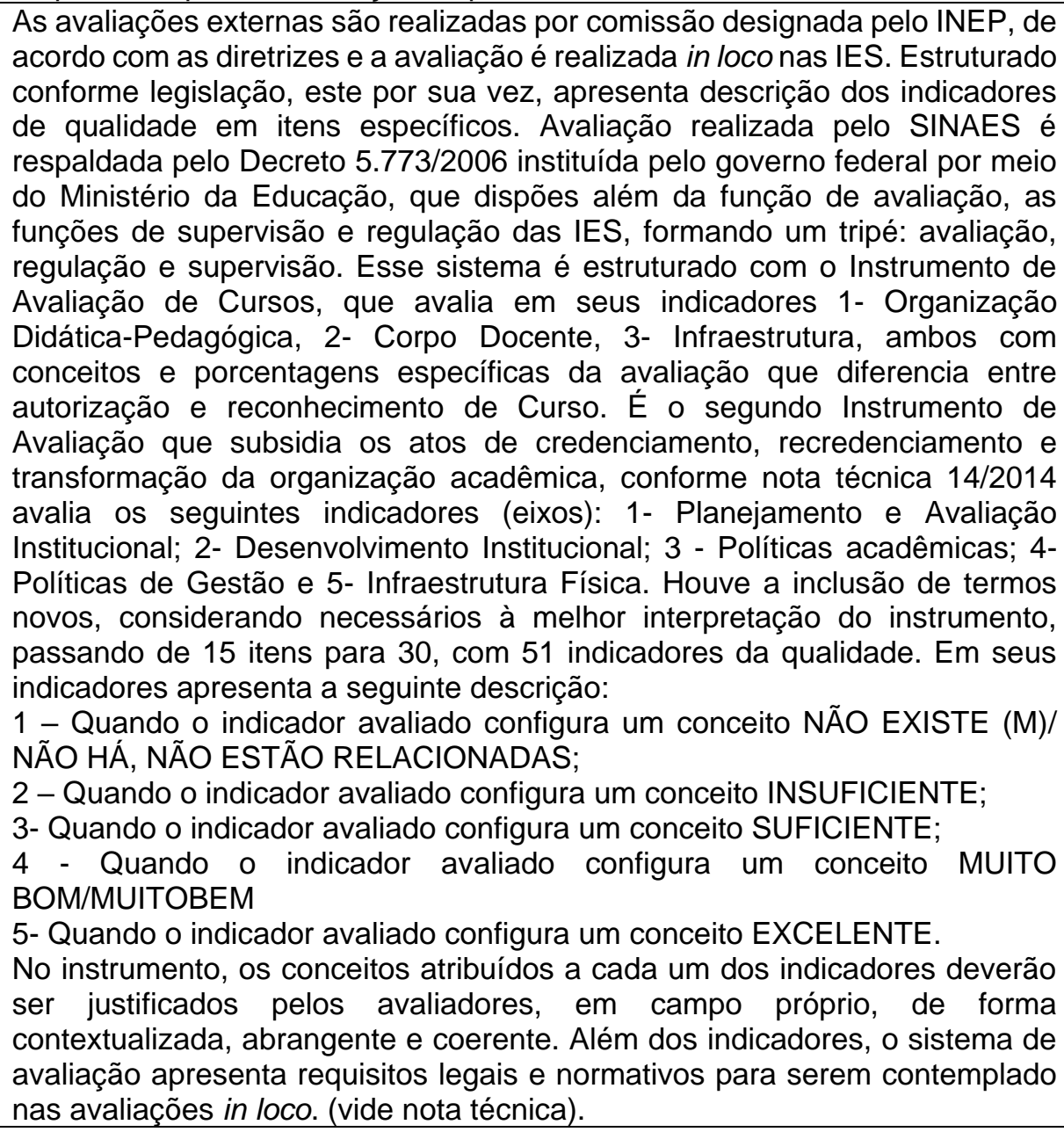 \\
\hline
\end{tabular}




\begin{tabular}{|c|c|}
\hline $\begin{array}{l}\text { Avaliação de } \\
\text { Desempenho }\end{array}$ & 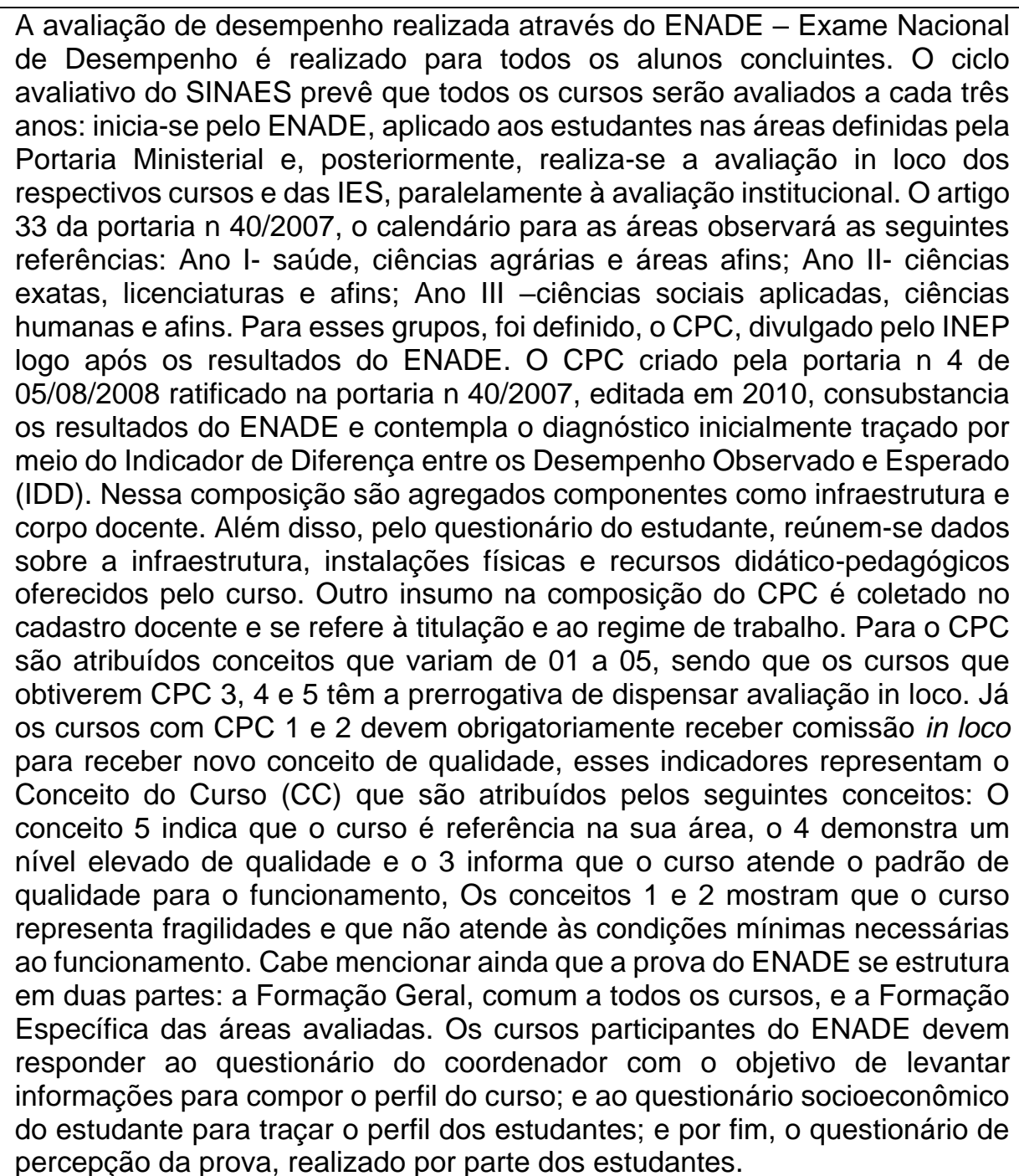 \\
\hline
\end{tabular}
Fonte: Poffo, 2018.

Vale ressaltar que não há dúvida de que avaliar cursos e instituições da educação superior pelo SINAES enquanto proposta de avaliação institucional fundamentada em princípios democráticos pretende resgatar importantes elementos da autoavaliação, como, por exemplo, colocando em evidencia a participação de todos os segmentos da instituição como forma de garantir o envolvimento e, por consequência, a continuidade do processo avaliativo, criando a cultura da avaliação (RIBEIRO, 2010). Legitimando o avanço competitivo das IES, e fortalecendo a obrigação da inovação no ensino superior foi promulgada legislação que ampara a curricularização da extensão dentro dos componentes curriculares dos cursos de graduação, podendo ser esclarecido no capítulo a seguir. 


\subsection{CURRICULARIZAÇÃO DA EXTENSÃO}

Em 18 de dezembro de 2018, por meio da Resolução no 07 de 17/12/2018, ficou estabelecida as Diretrizes para a Extensão na Educação Superior Brasileira e com ela a regimentação do disposto na Meta 12.7 da Lei no $13.005 / 2014$, que aprova o Plano Nacional de Educação - PNE 2014-2024 e outras providências institucionais. Caberá a cada IES organizar em seu Plano de Desenvolvimento Institucional (PDI) e Projeto Pedagógico de Curso (PPC), as normativas e resoluções institucionais que fidelizem a implantação desta regulação.

Com o intuito de fortalecer a formação acadêmica, a extensão torna-se um mecanismo de diferenciação e inovação que deverão estar condicionados no planejamento, nas políticas, na gestão e na avaliação das instituições de ensino superior. Determinadas por ato legislativo, a extensão deverá compor as matrizes curriculares de curso podendo ser ofertadas em parceria com organizações privadas ou públicas, ou mesmo com projeção administrativa e financeira da própria IES.

Em seu artigo segundo, está estabelecido que essas diretrizes educacionais deverão estar regulamentas como atividades de extensão nos cursos de graduação, na forma de componentes curriculares com a previsão nos Planos de Desenvolvimento Institucionais (PDIs), e nos Projetos Políticos Institucionais (PPIs) das entidades educacionais, de acordo com o perfil do egresso, estabelecido nos Projetos Pedagógicos dos Cursos (PPCs) e nos demais documentos normativos próprios.

Conforme resolução no 07 de 17/12/2018, em seus artigos, apresenta:

Art. 3o de A Extensão na Educação Superior Brasileira é a atividade que se integra à matriz curricular e à organização da pesquisa, constituindo-se em processo interdisciplinar, político educacional, cultural, científico, tecnológico, que promove a interação transformadora entre as instituições de ensino superior e os outros setores da sociedade, por meio da produção e da aplicação do conhecimento, em articulação permanente com o ensino e a pesquisa.

Art. 4ํㅡㄹ atividades de extensão devem compor, no mínimo, $10 \%$ (dez por cento) do total da carga horária curricular estudantil dos cursos de graduação, as quais deverão fazer parte da matriz curricular dos cursos;

Em sua estrutura, a extensão poderá ser classificada da seguinte forma, de acordo com artigo 5 da resolução no 07 de 17/12/2018:

I - a interação dialógica da comunidade acadêmica com a sociedade por meio da troca de conhecimentos, da participação e do contato com as questões complexas contemporâneas presentes no contexto social; II - a formação cidadã dos estudantes, marcada e constituída pela vivência dos seus conhecimentos, que, de modo interprofissional e interdisciplinar, seja valorizada e integrada à matriz curricular; III - a produção de mudanças na própria instituição superior e nos demais setores da sociedade, a partir da construção e aplicação de conhecimentos, bem como por outras atividades acadêmicas e sociais; IV - a articulação entre ensino/extensão/pesquisa, ancorada em processo pedagógico único, interdisciplinar, político educacional, cultural, científico e tecnológico.

As atividades extensionistas, são as intervenções que envolvam 
diretamente as comunidades externas às instituições de ensino superior e que estejam vinculadas à formação do estudante, nos termos desta Resolução, e conforme normas institucionais próprias. Segundo sua caracterização nos projetos políticos pedagógicos dos cursos, se inserem nas seguintes modalidades: I - programas; II - projetos; III - cursos e oficinas; IV - eventos; V prestação de serviços.

De acordo com a legislação, a extensão deve estar sujeita à contínua autoavaliação crítica, que se volte para o aperfeiçoamento de suas características essenciais de articulação com o ensino, a pesquisa, a formação do estudante, a qualificação do docente, a relação com a sociedade, a participação dos parceiros e a outras dimensões acadêmicas institucionais. Diante disso, de acordo com Rizzatti (2010), a avaliação institucional é compreendida como impulsionadora de mudanças no processo acadêmico de produção e disseminação de conhecimento, que se concretiza na formação de cidadãos e profissionais e no desenvolvimento de atividades de pesquisa e de extensão. Neste sentido, contribui para a formulação de caminhos para a transformação da educação superior, evidenciando o compromisso desta com a construção de uma sociedade mais justa e solidária e, portanto, mais democrática e menos excludente.

Com a obrigação de cumprir a legislação de ensino superior através da avaliação externa in loco institucional e de cursos, é de responsabilidade do Instituto Anísio Teixeira (INEP), autarquia vinculada ao Ministério da Educação (MEC) considerar e avaliar tal legislação para efeito de autorização, reconhecimento e renovação de reconhecimento de cursos, bem como para o credenciamento e recredenciamento das instituições de ensino superior, de acordo com o Sistema Nacional de Avaliação (SINAES), os seguintes fatores, entre outros que the couber:

Segundo resolução específica, aos acadêmicos fica condicionado a permissão de participar de quaisquer atividades de extensão, mantidas pelas instituições de ensino superior, respeitados os eventuais pré-requisitos especificados nas normas pertinentes. As atividades de extensão podem ser realizadas com parceria entre instituições de ensino superior, de modo que estimule a mobilidade interinstitucional de estudantes e docentes. 


\section{METODOLOGIA}

Para nortear essa pesquisa, utiliza-se como objetivo principal a proposição de uma matriz curricular para o curso de Administração com a implantação da legislação do MEC, Resolução CNE/ CES nำ 7 de 18 dezembro de 2018.

Este artigo é apresentado metodologicamente como um estudo de caso aplicado no curso de Administração, modalidade presencial. É um estudo de natureza básica e, por utilizar bases de referências documentais advindas de grupos focais, os quais participavam diretores e gestores da IES para discussão e avaliação da implantação da legislação instituída pelo MEC, baseia-se em um estudo qualitativo. Ainda, através dos caminhos metodológicos, utilizou como base para os objetivos a pesquisa descritiva e expositiva e, como procedimentos técnicos bibliográfica, documental e grupo focal.

As reuniões foram condicionadas pelos autores que, também, correspondem a área de gestão da própria IES, sendo estabelecida as participações da reitoria, pró-reitora acadêmica, gerente de extensão, gerente de ensino, gerente de pesquisa e procuradora institucional da IES. Nos encontros, os quais foi utilizado o método de grupo focal, ocorriam na sala da pró-reitora, local reservado a fim de garantir a privacidade da pesquisa.

Ao todo, foram necessárias 12 (doze) reuniões, com duração de, em média, 2 (duas) horas por semana para estruturação de um projeto piloto. Todas essas atividades de extensão foram registradas na documentação dos estudantes como forma de seu reconhecimento formativo dada a seriedade da ação desenvolvida.

Além da adequação da matriz curricular foi necessário elaborar um modelo de relatório de extensão para que no início de cada semestre letivo seja aprovado pelo gerente de extensão, o orçamento para as atividades com aprovação da reitoria, o planejamento das aulas e contextos para organização com os alunos e professores do semestre em vigor para desenvolvimento das atividades nas entidades comunitárias.

Em 2021/1 foi institucionalizado a funcionalidade da extensão em todas as primeiras fases dos cursos presenciais da IES, como modelo desta pesquisa, será apresentado a oferta da curricularização da extensão na matriz curricular do curso de administração, conforme pode ser observado no item a seguir. 


\section{RESULTADOS}

Conforme apresentado acima, a evolução legislativa para as IES acontece de forma constante e regular. O presente estudo, caracteriza a implantação da curricularização da extensão, de acordo com a Resolução ํㅜ 07 de 17 de dezembro de 2018 que estabelece as Diretrizes para a Extensão na Educação Superior Brasileira e regimenta o disposto na Meta 12.7 da Lei no 13.005/2014 que aprova o Plano Nacional de Educação - PNE 2014-2024, conforme pode ser observado abaixo:

\begin{tabular}{|c|c|c|c|c|c|c|}
\hline \multicolumn{7}{|c|}{ ADMINISTRAÇÃ } \\
\hline $\begin{array}{l}\text { Grau } \\
\text { Bacharel }\end{array}$ & \multicolumn{3}{|c|}{$\begin{array}{l}\text { Periodicidade de Oferta } \\
\qquad \text { Semestral }\end{array}$} & \multicolumn{2}{|c|}{$\begin{array}{l}\text { Periodicidade Total } \\
08 \text { semestres }\end{array}$} & $\begin{array}{l}\text { Modalidade: } \\
\text { Presencial }\end{array}$ \\
\hline \multicolumn{7}{|c|}{ CARGA HORÁRIA DO CURSO (Hora Relógio) } \\
\hline $\begin{array}{c}\text { Carga Horária Total } \\
3.036 \mathrm{~h}\end{array}$ & $\begin{array}{l}\text { A Distância } \\
789 h(25,99 \%)\end{array}$ & $\begin{array}{l}\text { Estágio } \\
304 \mathrm{~h}\end{array}$ & $\begin{array}{l}\text { Ativ. Comp. } \\
\text { 300h }\end{array}$ & $\begin{array}{l}\text { Curric. Extensão } \\
\text { 320h }\end{array}$ & $\begin{array}{l}\text { TCC } \\
\text { NSA }\end{array}$ & $\begin{array}{l}\text { Libras } \\
\text { 76h (optativa) }\end{array}$ \\
\hline
\end{tabular}

\begin{tabular}{|l|c|c|c|c|}
\hline \multicolumn{3}{|c|}{$1^{\circ}$ SEMESTRE } \\
\hline \multirow{2}{*}{ COMPONENTES CURRICULARES } & \multicolumn{3}{c|}{ CARGA HORÁRIA } \\
\cline { 2 - 5 } & Teoria & EAD & $\begin{array}{c}\text { Extensã } \\
\text { 0 }\end{array}$ & TOTAL \\
\hline Metodologia do Trabalho Acadêmico & - & 66 & 10 & 76 \\
\hline Fundamentos de Gestão & 49 & 17 & 10 & 76 \\
\hline Mercado de Trabalho e Carreira & 49 & 17 & 10 & 76 \\
\hline Comunicação e Endomarketing & 49 & 17 & 10 & 76 \\
\hline \multicolumn{1}{|c|}{ Subtotal } & $\mathbf{1 4 7}$ & $\mathbf{1 1 7}$ & $\mathbf{4 0}$ & $\mathbf{3 0 4}$ \\
\hline
\end{tabular}

\begin{tabular}{|c|c|c|c|c|}
\hline \multicolumn{5}{|c|}{ 2 SEMESTRE } \\
\hline \multirow[b]{2}{*}{ COMPONENTES CURRICULARES } & \multicolumn{4}{|c|}{ CARGA HORÁRIA } \\
\hline & Teoria & EAD & $\begin{array}{c}\text { Extensã } \\
0\end{array}$ & TOTAL \\
\hline Matemática Básica e Financeira & 49 & 17 & 10 & 76 \\
\hline Introdução ao Direito & 49 & 17 & 10 & 76 \\
\hline Gestão de Logística & 49 & 17 & 10 & 76 \\
\hline Filosofia, Ética, Direitos Humanos e Cidadania & - & 66 & 10 & 76 \\
\hline Subtotal & 147 & 117 & 40 & 304 \\
\hline
\end{tabular}

\begin{tabular}{|l|c|c|c|c|}
\hline \multicolumn{5}{|c|}{ 3o SEMESTRE } \\
\hline \multirow{2}{*}{ COMPONENTES CURRICULARES } & \multicolumn{4}{|c|}{ CARGA HORÁRIA } \\
\cline { 2 - 5 } & Teoria & EAD & $\begin{array}{c}\text { Extensã } \\
\mathbf{0}\end{array}$ & TOTAL \\
\hline Contabilidade Geral e Gerencial & 49 & 17 & 10 & 76 \\
\hline Estatística & 49 & 17 & 10 & 76 \\
\hline $\begin{array}{l}\text { Sociologia, Estudos Antropológicos e Relações } \\
\text { Étnico Raciais }\end{array}$ & - & 66 & 10 & 76 \\
\hline Gestão de Marketing & 49 & 17 & 10 & 76 \\
\hline \multicolumn{1}{|c|}{ Subtotal } & $\mathbf{1 4 7}$ & $\mathbf{1 1 7}$ & $\mathbf{4 0}$ & $\mathbf{3 0 4}$ \\
\hline
\end{tabular}




\begin{tabular}{|c|c|c|c|c|}
\hline \multicolumn{5}{|c|}{ 4온 SEMESTRE } \\
\hline \multirow[b]{2}{*}{ COMPONENTES CURRICULARES } & \multicolumn{4}{|c|}{ CARGA HORÁRIA } \\
\hline & Teoria & EAD & $\begin{array}{c}\text { Extensã } \\
0\end{array}$ & TOTAL \\
\hline Direito Empresarial e Tributário & 49 & 17 & 10 & 76 \\
\hline Gestão de Pessoas e Equipe & 49 & 17 & 10 & 76 \\
\hline Economia & - & 66 & 10 & 76 \\
\hline Gestão Financeira e Orçamentária & 49 & 17 & 10 & 76 \\
\hline Subtotal & 147 & 117 & 40 & 304 \\
\hline \multicolumn{5}{|c|}{ 5o SEMESTRE } \\
\hline \multirow[b]{2}{*}{ COMPONENTES CURRICULARES } & \multicolumn{4}{|c|}{ CARGA HORÁRIA } \\
\hline & Teoria & EAD & $\begin{array}{c}\text { Extensã } \\
0\end{array}$ & TOTAL \\
\hline Gestão Socioambiental & 49 & 17 & 10 & 76 \\
\hline Psicologia Organizacional & - & 66 & 10 & 76 \\
\hline Administração da Produção & 49 & 17 & 10 & 76 \\
\hline Marketing de Serviço - e-commerce & 49 & 17 & 10 & 76 \\
\hline Subtotal & 147 & 117 & 40 & 304 \\
\hline
\end{tabular}

\begin{tabular}{|l|c|c|c|c|}
\hline \multicolumn{5}{|c|}{ 6 } \\
\multirow{2}{*}{ COMPMESTRE } \\
\cline { 2 - 5 } & \multicolumn{4}{|c|}{ CARGA HORÁRIA } \\
\hline Legislação Social, Trabalhista e Previdenciária & Teoria & EAD & $\begin{array}{c}\text { Extensã } \\
\mathbf{0}\end{array}$ & TOTAL \\
\hline Organização, Sistemas e Métodos & 49 & 17 & 10 & 76 \\
\hline Tecnologia e práticas inovadoras & 49 & 17 & 10 & 76 \\
\hline Negociação e Processo Decisório & 49 & 17 & 10 & 76 \\
\hline \multicolumn{1}{|c|}{ Subtotal } & 49 & 17 & 10 & 76 \\
\hline
\end{tabular}

\begin{tabular}{|l|c|c|c|c|}
\hline \multicolumn{5}{|c|}{$7^{\circ}$ SEMESTRE } \\
\hline \multirow{2}{*}{ COMPONENTES CURRICULARES } & \multicolumn{4}{|c|}{ CARGA HORÁRIA } \\
\cline { 2 - 5 } & Teoria & EAD & $\begin{array}{c}\text { Extensã } \\
\mathbf{0}\end{array}$ & TOTAL \\
\hline Administração de Projetos & 49 & 17 & 10 & 76 \\
\hline Administração Estratégica - Business Games & 49 & 17 & 10 & 76 \\
\hline Consultoria Empresarial & 49 & 17 & 10 & 76 \\
\hline Gestão da Qualidade & 49 & 17 & 10 & 76 \\
\hline Estágio Supervisionado I & 152 & - & - & 152 \\
\hline \multicolumn{1}{|c|}{ Subbtotal } & $\mathbf{3 4 8}$ & $\mathbf{6 8}$ & $\mathbf{4 0}$ & $\mathbf{4 5 6}$ \\
\hline
\end{tabular}

\begin{tabular}{|c|c|c|c|c|}
\hline \multicolumn{5}{|c|}{ 8 SEMESTRE } \\
\hline \multirow[b]{2}{*}{ COMPONENTES CURRICULARES } & \multicolumn{4}{|c|}{ CARGA HORÁRIA } \\
\hline & Teoria & EAD & $\begin{array}{c}\text { Extensã } \\
0\end{array}$ & TOTAL \\
\hline Empreendedorismo & 49 & 17 & 10 & 76 \\
\hline Gestão do Conhecimento & 49 & 17 & 10 & 76 \\
\hline Modelo de Negócios & 49 & 17 & 10 & 76 \\
\hline Optativa & 49 & 17 & 10 & 76 \\
\hline Estágio Supervisionado II & 152 & - & - & 152 \\
\hline
\end{tabular}




\begin{tabular}{|c|c|c|c|c|}
\hline Subtotal & 348 & 68 & 40 & 45 \\
\hline \multicolumn{5}{|c|}{ QUADRO RESUMO } \\
\hline \multicolumn{2}{|l|}{ COMPONENTES CURRICULARES } & \multicolumn{2}{|c|}{ CARGA HORÁRIA } & $\%$ \\
\hline - Conteúdos Teórico-Práticos & & \multicolumn{2}{|c|}{1.323} & $43,57 \%$ \\
\hline - Estágio Obrigatório & & \multicolumn{2}{|l|}{304} & $10,01 \%$ \\
\hline - Atividades Complementares & & \multicolumn{2}{|l|}{300} & $9,88 \%$ \\
\hline - Carga Horária EAD & & \multicolumn{2}{|l|}{789} & $25,98 \%$ \\
\hline - Curricularização da Extensão & & \multicolumn{2}{|l|}{320} & $10,54 \%$ \\
\hline CARGA HORÁRIA TOTAL DO CURSO & & \multicolumn{2}{|c|}{3.036} & $100 \%$ \\
\hline
\end{tabular}

A proposta acima direcionadas na matriz curricular do curso de administração, prevê atividades de extensão ao longo da oferta em todas as disciplinas do curso, compondo a sua obrigatoriedade mínima, de 10\% (dez por cento) do total da carga horária curricular estudantil dos cursos de graduação as quais deverão fazer parte da matriz curricular dos cursos.

A gestão e oferta das atividades de extensão foram desenvolvidas pelos coordenadores de curso, e conforme previsto na legislação, condicionada pelo professor para emissão de avaliação, elaboração de relatório e feedbacks das potencialidades e fragilidades que serão gerenciadas na autoavaliação continuada da extensão.

De acordo com a previsão legislativa, as atividades de extensão foram devidamente registradas, documentadas e analisadas, de forma que seja possível organizar os planos de trabalho, as metodologias, os instrumentos e os conhecimentos gerados pela comunidade acadêmica. As atividades de extensão foram sistematizadas e acompanhadas, com o adequado assentamento, além de registradas, fomentadas e avaliadas por instâncias administrativas institucionais, devidamente estabelecidas, em regimento próprio.

\section{CONCLUSÃO}

O princípio proposto para a institucionalização da Curricularização da Extensão é a organização de projetos que contemplem pesquisa, a interdisciplinaridade, as multiculturas e as tecnologias, unindo, ainda mais, a tríade ensino, pesquisa e extensão. Esta interação é o agente promotor da transformação de Instituições de Ensino Superior em ambientes abertos à comunidade, formador de cidadãos críticos e preocupados com a sociedade e engajados na resolução de problemas. 
Com isto, como conclusão do estudo, é possível identificar que a implantação dessa legislação fortalecerá a formação do acadêmico desenvolvendo novas habilidades técnicas e profissionais, qualificando o aluno para o mercado de trabalho mais competitivo, dinâmico e inovador. $E$, além disto, estimula a participação dos acadêmicos em projetos extraclasse, firmando parcerias com a comunidade, incluindo os profissionais técnico-administrativos, qualificando os professores e valorizando e oportunizando as boas ações através de projetos reais. 


\section{REFERÊNCIAS}

BRASIL, Decreto n 91.177 , de 29 de março de 1985. Institui a Comissão Nacional visando à reformulação da Educação Superior, e dá outras providências. Diário Oficial da União, seção 1, Brasília, DF, p. 5651, 1985.

, Lei $\mathrm{n}^{\circ}$ 9.131, de 24 de novembro de 1995. Altera os dispositivos da Lei $\mathrm{n}^{\circ}$ 4. 024, de 20 de dezembro de 1961, e dá outras providências. Diário Oficial da União, seção 1, edição extra, Brasília, DF, p. 19257, 1995.

, Lei $\mathrm{n}^{\circ}$ 9.394, de 20 de dezembro de 1996. Estabelece as diretrizes e bases da educação nacional. Diário Oficial da União: seção 1, Brasília, DF, p. 27839, 1996.

Decreto $n^{\circ} 5.773$, de 9 de maio de 2006. Dispõe sobre o exercício das funções de regulação, supervisão e avaliação de instituições de Educação Superior e cursos superiores de graduação e sequenciais no sistema federal de ensino. Diário Oficial da União: seção 1, Brasília, DF, p. 6, 2006.

, Portaria Normativa $n^{\circ} 40$, de 29 de dezembro de 2010. Institui o e-Mec, sistema eletrônico de fluxo de trabalho e gerenciamento de informações relativas aos processos de regulação, avaliação e supervisão da Educação Superior no Sistema Federal de Educação, e o Cadastro e-Mec de Instituições e Cursos Superiores e consolida disposições sobre indicadores de qualidade, banco de avaliadores (Basis) e o Exame Nacional de Desempenho de Estudantes (ENADE) e outras disposições. Diário Oficial da União: seção 1, Brasília, DF, p. 39-43, 2007.

, Instituto Nacional de Estudos e Pesquisas Educacionais Anísio Teixeira. Plano Nacional de Educação - PNE 2014/2024: Linha de Base. Brasília, DF: INEP, 2015.

, Instituto Nacional de Estudos e Pesquisas Educacionais Anísio Teixeira - INEP. Sistema Nacional de Avaliação da Educação Superior (SINAES/INEP). Brasília, DF: INEP, 2016.

Portaria Normativa $n^{\circ} 10$, de 18 de maio de 2017. Altera o inciso IV do art. 57 da Portaria Normativa MEC n 40, de 12 de dezembro de 2007, e dá outras providências. Diário Oficial da União: seção 1, Brasília, DF, p. 12, 2017.

, Portaria $n^{\circ} 1.383$, de 31 de outubro de 2017. Aprova, em extrato, os indicadores do Instrumento de Avaliação de Cursos de Graduação para os atos de autorização, reconhecimento e renovação de reconhecimento nas modalidades presencial e a distância do Sistema Nacional de Avaliação da Educação Superior - SINAES. Diário Oficial da União: seção 1, Brasília, DF, p. 15, 2017.

, Portaria $n^{\circ}$ 9.235, de 15 de dezembro de 2017. Dispõe sobre o exercício das funções de regulação, supervisão e avaliação das instituições de Educação Superior e dos cursos superiores de graduação e de pós-graduação no Sistema Federal de Ensino. Diário Oficial da União: seção 1, Brasília, DF, p. 2-5, 2017. 
, Portaria Normativa $\mathrm{n}^{\circ} 20$, de 21 de dezembro de 2017. Dispõe sobre os procedimentos e o padrão decisório dos processos de credenciamento, recredenciamento, autorização, reconhecimento e renovação de reconhecimento de cursos superiores, bem como seus aditamentos, nas modalidades presencial e a distância, das Instituições de Educação Superior do Sistema Federal de Ensino. Diário Oficial da União: seção 1, Brasília, DF, p. 25-29, 2017.

Portaria Normativa $n^{\circ} 21$, de 21 de dezembro de 2017. Dispõe sobre o sistema e-Mec, sistema eletrônico de fluxo de trabalho e gerenciamento de informações relativas aos processos de regulação, avaliação e supervisão da Educação Superior no Sistema Federal de Educação, e o Cadastro Nacional de Cursos e Instituições de Educação Superior Cadastro e-Mec. Diário Oficial da União: seção 1, Brasília, DF, p. 29-33, 2017.

, Portaria Normativa $n^{\circ} 22$, de 21 de dezembro de 2017. Dispõe sobre os procedimentos de supervisão e monitoramento de Instituições de Educação Superior e de cursos superiores de graduação e de pós-graduação lato sensu, nas modalidades presencial e a distância, integrantes do Sistema Federal de Ensino. Diário Oficial da União: seção 1, Brasília, DF, p. 33-35, 2017.

, Portaria Normativa $n^{\circ} 23$, de 21 de dezembro de 2017. Dispõe sobre o fluxo dos processos de credenciamento e recredenciamento de instituições de educação superior e de autorização, reconhecimento e renovação de reconhecimento de cursos superiores, bem como seus aditamentos. Diário Oficial da União: seção 1, Brasília, DF, p. 35-40, 2017.

Resolução $n^{\circ} 7$, de 18 de dezembro de 2018. Estabelece as Diretrizes para a Extensão na Educação Superior Brasileira e regimenta o disposto na Meta 12.7 da Lei $n^{\circ}$ 13.005/2014, que aprova o Plano Nacional de Educação - PNE 2014-2024 e dá outras providências. Diário Oficial da União: seção 1, Brasília, DF, p. 34, 2018.

DIAS SOBRINHO, J. Dilemas da Educação Superior no mundo globalizado: sociedade do conhecimento ou economia do conhecimento? São Paulo: Casa do Psicólogo, 2010.

FARIA, A. C. et al. O grau de satisfação dos alunos do curso de ciências contábeis: busca e sustentação da vantagem competitiva de uma IES privada. Enfoque Reflexão Contábil, v. 25, n. 1, p. 25-36, 2006.

GARCIA, M.; VIANNA, N. M. V.; SUÑÉ, L. S. de V. S. Diagnósticos e Propostas para a Avaliação da Educação Superior no Brasil. Brasília: ABMES Editora, 2012.

LINS, M. T. G.; TEIXEIRA, R. M., BARBOSA, J. D. Gestão da Qualidade em IES: Percepção das ações estratégicas e operacionais pelos discentes, docentes e gestores. V Colóquio Internacional sobre Gestion Universitaria en America del Sur, 2005.

MOROSINI, M. C. Qualidade da educação superior e contextos emergentes. 
Avaliação, Campinas; Sorocaba, SP, v. 19, n. 2, p. 385-405, jul., 2014.

POFFO, G. D. Modelo de avaliação da qualidade dos serviços para Instituições de Ensino Superior. 2018. Tese de doutorado. Doutorado Acadêmico em Administração e Turismo. Universidade do Vale do Itajaí - UNIVALI. Biguaçu, 2018. Disponível em http://siaibib01/PDF/Gabriella\%20Depine\%20Poffo.pdf Acesso em 07 out 2021.

RIBEIRO, E. A. O processo de autoavaliação institucional proposto no sistema nacional de avaliação da educação superior (SINAES) para as instituições públicas e privadas. 320 p. Tese (Doutorado) - Programa de pós-graduação em administração na Universidade Federal de Uberlândia, Uberlândia, 2010.

RIZZATTI, G.; et. al. Programa de Qualidade para Universidades Públicas e privadas: na perspectiva da melhoria de serviços prestados aos múltiplos usuários. X Colóquio Internacional sobre Gestión Universitaria en America del Sur, Mar Del Plata, dez., 2010.

WALTER, S. A.; TONTINI, G.; DOMINGUES, M. J. C. S. Identificando oportunidades de melhoria em um curso superior através da análise da satisfação dos alunos. In: Encontro Nacional Dos Programas De Pós-graduação Em Administração. Brasília, 2005. Anais. CD-ROM, Rio de Janeiro: ANPAD, 2005. 